\title{
GCU
}

Glasgow Caledonian

University

University for the Common Good

\section{The health visitor role in containing antimicrobial resistance}

Reilly, Jacqui; Ness, Valerie; MacDonald, Emma

Published in:

Journal of Health Visiting

DOI:

10.12968/johv.2017.5.8.386

Publication date:

2017

Document Version

Author accepted manuscript

Link to publication in ResearchOnline

Citation for published version (Harvard):

Reilly, J, Ness, V \& MacDonald, E 2017, 'The health visitor role in containing antimicrobial resistance', Journal of Health Visiting, vol. 5, no. 8, pp. 386-390. https://doi.org/10.12968/johv.2017.5.8.386

\section{General rights}

Copyright and moral rights for the publications made accessible in the public portal are retained by the authors and/or other copyright owners and it is a condition of accessing publications that users recognise and abide by the legal requirements associated with these rights.

Take down policy

If you believe that this document breaches copyright please view our takedown policy at https://edshare.gcu.ac.uk/id/eprint/5179 for details of how to contact us. 
TITLE PAGE

Title:

The important role of the health visitor in containing Antimicrobial Resistance

Author details:

Reilly JS

Professor of Infection prevention at Glasgow Caledonian University and

Lead consultant for HAI, AMR and IPC at Health Protection Scotland

Ness $V$

PhD Student and Lecturer

Glasgow Caledonian University

MacDonald E

Lecturer

Glasgow Caledonian University

\section{Corresponding author details:}

Prof Jacqui Reilly

Safeguarding Health through Infection Prevention Research Group Lead A510 Govan Mbeki Building

Glasgow Caledonian University

Cowcaddens Road

Glasgow

Tel: 01413313323

Email: Jacqui.reilly@gcu.ac.uk 


\begin{abstract}
This article discusses the importance of the role of the health visitor in the containment of Antimicrobial Resistance, focusing on three key areas of practice. Antimicrobial resistance is a huge public health problem and all health professionals should be engaged in preserving antibiotics for future generations. The focus of this article will discuss the health visitor's role in infection prevention and control, antibiotic stewardship and prescribing, and improving public engagement and professional development in antibiotic stewardship and Infection Prevention and Control.
\end{abstract}

\title{
Introduction to Antimicrobial Resistance
}

Antimicrobial resistance (AMR) occurs when a microbe mutates or acquires genetic information from another microbe, making it resistant to antibiotics. There are many contributing factors, one being antibiotic use in humans, most of which are prescribed in primary care (74\%) (English surveillance programme for antimicrobial utilisation and resistance (ESPAUR) 2016). In addition, a recent prevalence survey in Scotland demonstrated that around one in three hospital patients are on at least one antibiotic at any one time (Health Protection Scotland (HPS) 2017). Antimicrobial Resistance is also related to antibiotic use in animals, including farming and food production, and the environment (Michael et al 2014). In essence it is Darwin's theory of evolution, the "survival of the fittest", occurring at a microbe level. This makes AMR difficult to see and conceptualise and there have been recent calls for better communication and language about AMR for healthcare professionals, and the public (Mendelson et al 2017). It is very important that the risk is understood and this article focuses specifically on the need for health visitors to be engaged in the agenda of containing AMR.

\section{The Burden of Antimicrobial Resistance}

Antimicrobial Resistance has been declared one of the greatest threats to global health (WHO 2016a) on the basis of the ' 3 Ds' of public health: distress, disability and death. It is the cause of an estimated 700000 deaths per year globally and, in the European Union 
alone it is estimated to cost 1.5 billion Euros in healthcare and productivity losses (European Commission 2017). The response to this requires international effort as resistant organisms know no country borders, do not have to go through security control, and are therefore easily imported from one country to another. The World Health Organisation (WHO 2017a), this year, published a list of the priority AMR pathogens, some of which were classed as being critical threats (see Table 1). As might be expected it is the healthcare associated pathogens which feature as critical, predominantly gram negative bacteria, and it is this current threat that we should be concerned about in the United Kingdom (UK). However, there are also community specific threats, as detailed in the high and medium priorities, which mean a population effort is required to contain AMR.

Given the international threat of AMR, the UK government commissioned Lord O'Neil to carry out a review to examine the economics of AMR for the $G 7$, inclusive of projections of the impact if nothing was done to contain the threat (O'Neil 2016). The review pointed to what might happen if we do not control AMR and estimated that we would return to a preantibiotic era with a $43 \%$ attributable mortality, resulting in 10 million deaths worldwide by 2050. This estimated mortality was greater than any other disease including cancers, road traffic accidents and diarrhoeal illness. As a result of this, the Chief Medical Officer (CMO) from the UK government, said it was "arguably as important as climate change" (CMO 2011) and it was placed on the UK risk register. Whilst the O'Neil report has been criticised for oversimplifying the costs and being based on very limited evidence (de Kraker et al 2016) it should be noted that it was only based on three of the critical types of AMR and is thus an underestimate of all AMR impact.

A new global call to action from the G7, and other key international organisations such as WHO and the World Economic Forum (WEF 2017), arose from this work and from nursing leadership as a key policy area (Hughes 2016; Royal College of Nursing (RCN) 2014). This literature points to the role that nurses and midwives should play in reducing the risk of $A M R$, and relates specifically to the national and international action plans developed by many countries in response to the problem. The UK AMR action plan (Department of Health (DoH) 2013) has seven action areas (detailed in Table 2). Action areas one to three are where health visitors, in their day to day interactions and role, can support this agenda and so will be the focus of the remainder of this article. 


\section{Actions for Health Visitors in Containing AMR}

There are three main action areas for health visitors in contributing to the containment of AMR. The first is improving infection prevention and control (IPC) in human health, the second is antibiotic stewardship and prescribing and the third is improving public engagement and professional development in antibiotic stewardship and IPC. Each of these will now be addressed in turn.

\section{Action area 1 for health visitors: Improving infection prevention and control in human health (IPC and vaccination)}

Preventing infections in the population

Preventing the infection from occurring in the first place is the best way to preserve the use of antibiotics and save patients from distress caused by infections. Respiratory and gastrointestinal infections are a major cause of childhood illness, with poor respiratory etiquette and hand hygiene contributing to increased spread. The consequences and impact of these infections in children and young people have far-reaching implications, including school absences, spread of infection to other family members and therein sickness absence from work. Health visitors have a fundamental role in health protection. Helping children, parents and the wider family to understand the importance of hand hygiene in protecting their own health and that of their family and friends is key. The same responsibility also lies with us all, as professionals.

We have a professional responsibility to employ standard infection control precautions for every patient or child, every time, to prevent the potential risk of infection transmission (National Health Service, National Services Scotland (NHS NSS) 2012). Practices such as hand hygiene, safely managing waste and sharps, risk assessment and use of personal protective equipment such as gloves, are fundamental to health visiting practice. It sounds easy to do but even the simplest, most important measure, namely hand hygiene, is not carried out optimally. The WHO (2017b) organised the world hand hygiene day campaign this year on the $5^{\text {th }}$ May with a call to action to: 'clean hands, save lives and contain AMR'. This is 
because even when healthcare workers in high income countries are trained in the technique for hand hygiene, have the instructions in front of them, and know they are being watched for the purposes of a study, they only comply $65 \%$ of the time. This indicates that behavioural factors are important in the improvement of hand hygiene (Reilly et al 2016).

Demonstrating appropriate hand hygiene, during home visits and clinic appointments can change behaviour through role modelling. There may also be the opportunity to discuss infection prevention measures in greater detail when there is a specific need, for example, during outbreaks, after administering a live vaccine or if there is a recurrence of infection e.g. worms.

\section{The importance of vaccination}

Dispelling the myths of vaccination is the second area of focus for heath visitors. The WHO (2017c) have produced very helpful evidence based question and answer information to dispel the current myths on safety, immunity, multiple vaccination at one time, preservatives and autism. This is a helpful reference point for all health visitors. Increasing uptake of vaccinations via our advocacy role, both for the public and for our own professional colleagues is also important. Increased uptake of vaccinations is directly related to immunisation effectiveness. Each year immunisation averts an estimated 2-3 million deaths globally (WHO 2017d) thus preventing avoidable infections via vaccination is crucial to avoiding the unnecessary infections and subsequent use of antimicrobials and antivirals. This can be evidenced in a retrospective observational study which assessed the impact of Objective Rotavirus (OR) vaccination on paediatric hospital admissions in Lothian. In the two years following the vaccine introduction, the annual number of RV gastroenteritis admissions fell by $84.7 \%$, bed days reduced by $91.1 \%$ and suspected hospital acquired infections reduced by $95.7 \%$ (Forrest et al 2016).

In the Public Health England (PHE) (2016) framework for personalised care and population health for Nurses, Midwives, Health Visitors and Allied Health Professionals, the focus is on 'Making Every Contact Count'. This points to the role of health visitors working with the public, in providing opportunistic and timely advice on health to patients/service users, their carers, staff and communities with which they come into contact. Therefore, a key action for 
health visitors is to promote and provide immunisations to protect individual, community and population health from diseases and therein avoid the need for antibiotics and antivirals and contain AMR.

\section{Action area 2: Optimising prescribing practice}

Health visitors have a clear role in the safe management of medicines and can also act as advocates, antibiotic guardians (PHE 2017) and advisors with every contact, reinforcing the public health message of 'you don't need antibiotics for coughs and colds', and where antibiotics are needed; reinforcing the importance of completing the course, not sharing them with others and disposing of unused medication appropriately.

Health visitors are also prescribers and whilst this is well regulated, in the UK and many other countries, results of a national survey of health visitors' prescribing practice revealed variations in practice and support (Bishop and Gilroy 2015). Recommendations included the need to re-engage health visitors with how prescribing skills can deliver better outcomes for children, families and communities. This seems particularly important for antimicrobial prescribing and yet little is known about the prescribing practices of community nurses and health visitors with respect to antimicrobials. A Scottish study (Ness et al 2015) was the first to examine this issue and found that there has been a steady increase in the amount of antimicrobial prescribing in primary care undertaken by nurse prescribers. Evidence suggests that nurse prescribers give more advice about self-management, have longer consultations and provide more information to patients (RCN 2012). Therefore, health visitor prescribers are in an ideal position to educate their clients, even if they themselves rarely prescribe antimicrobials, about the differences between viral and bacterial infections and how to self-manage their symptoms. If an antimicrobial is necessary then selection of the most appropriate one, along with patient education about how to take them properly, is a key part of this role. 


\section{Action area 3: Improving professional education and public engagement}

In a WHO multi-country public awareness survey about AMR (WHO 2015a), levels of awareness and understanding around the issues and how to address them were mixed. Participants recognised the problem but did not fully understand what caused it or what to do about it. Another WHO report also found a lack of awareness within health care workers (WHO 2015b) and so it could be argued that awareness raising is necessary for the public and for healthcare workers who are not specialists in IPC.

Understandably when an illness occurs, be it an upper respiratory tract infection in an individual in the community, or an outbreak in a school, parents and the public at large may wish to ask their General Practitioner for antibiotics as a solution. Research, from medical and nursing literature suggests that managing patient expectations about antibiotics can be challenging for healthcare professionals (Mustafa et al 2014). All healthcare professionals have a responsibility to ensure there is an understanding of when it is appropriate to use antibiotics and when it is not (National Institute for Health and Care Excellence (NICE) 2017). Health visitors have a unique connection with parents and children in early years, and an opportunity therein to influence the public. In this way, we will help develop a new generation who understand about the use of antibiotics and can help tackle the global AMR challenge.

To support this education in the early years there are excellent, free teaching resources, endorsed by NICE and produced by Public Health England, called e-Bug (e-Bug 2017). This educational software package can be used to help children and young people understand how infections spread and how antimicrobial resistance develops. Reinforcement of key messages through the pre- and school-aged years will support long-term behaviour change. With the challenges of health visitor workload it may be that this role is better suited to those working within the nursery setting and therefore health visitors, who have links to nurseries, may be able to encourage their nursery colleagues to engage in this important education. 
Professional education and development is also important. Recommendations, again from a recent UK survey of health visitors (Bishop and Gilroy 2015), pointed to the necessity to develop consistent, high-quality continuing professional development (CPD) around prescribing for health visitors. There also needs to be a focus on antibiotic stewardship and IPC practice in this regard.

\section{Conclusion}

AMR is a major public health threat worldwide and there is an international call to action for all disciplines to engage in playing their part in this important agenda. The health visitor contribution to this agenda is threefold: in improving infection prevention and control in human health, antibiotic stewardship and prescribing, and in improving public engagement and professional development in antibiotic stewardship and IPC. By focussing on these actions health visitors can ensure they maximise their contribution to containing AMR.

\section{Key points}

- $A M R$ has been referred to as one of the greatest threats to public health with a projected attributable mortality of 50 million people a year globally by 2050

- The health visitor contribution to this agenda is threefold: in improving infection prevention and control in human health, antibiotic stewardship and prescribing, and in improving public engagement and professional development in antibiotic stewardship and IPC.

- Our IPC contribution involves maximising the potential uptake of vaccinations and infection control precautions to prevent the infections in the first place, hence negating the need for unnecessary antibiotics

- Consistent, high-quality public engagement and education, and continuing professional development (CPD) around prescribing for health visitors is needed with a focus on antibiotic stewardship and IPC practice in this regard 


\section{Key words}

Nurses, community health

Drug resistance, bacterial

Prevention and control

Infection

Public Health

\section{Statement of contributorship}

JR first authored based on a presentation given to the JHV conference in 2017. VN made substantial contribution to the review and interpretation of papers included. EMcD contributed as an experienced HV inclusive of context specific contribution of studies and analysis of these. JR, VN and EMcD participated in drafting the article or revising it critically for important intellectual content; and gave final approval of the version to be submitted and any revised version.

\section{References:}

Bishop P, Gilroy V. 2015 Non medical prescribing by health visitors in 2015 http://www.magonlinelibrary.com/doi/abs/10.12968/npre.2015.13.8.390?journalCode=npr e\& (accessed $2^{\text {nd }}$ June 2017)

CMO (2011) Annual Report of the Chief Medical Officer Volume Two, 2011 Infections and the rise of antimicrobial resistance. http://media.dh.gov.uk/network/357/files/2013/03/CMO-Annual-Report-Volume-220111.pdf (accessed $2^{\text {nd }}$ June 2017)

de Kraker MEA, Stewardson AJ, Harbarth S. (2016) Will 10 million people die a year due to Antimicrobial Resistance by 2050? PLOS, November 29, 2016. https://doi.org/10.1371/journal.pmed.1002184 [accessed $2^{\text {nd }}$ June 2017)

DoH (2013) UK Five year Antimicrobial Resistance Strategy 2013 to 2018. https://www.gov.uk/government/uploads/system/uploads/attachment data/file/244058/2 0130902 UK 5 year AMR strategy.pdf (accessed $2^{\text {nd }}$ June 2017)

Ebug (2017) Fun games and teaching resources about microbes and antibiotics. http://www.e-bug.eu/ (accessed $2^{\text {nd }}$ June 2017) 
ESPAUR (2016) English surveillance programme for antimicrobial utilisation and resistance (ESPAUR) Report 2016, Public Health England. https://www.gov.uk/government/uploads/system/uploads/attachment data/file/575626/E SPAUR Report 2016.pdf (accessed $2^{\text {nd }}$ June 2017)

European Commission (2017) Antimicrobial Resistance. http://ec.europa.eu/dgs/health food-safety/amr/index en.htm (accessed $2^{\text {nd }}$ June 2017)

Forrest R, Jones L, Willocks L, Hardie A, Templeton K (2017) Impact of the introduction of rotavirus vaccination on paediatric hospital admission, Lothian, Scotland: a retrospective observational study Arch Dis Child 102:323-327 doi: 10.1136/archdischild-2016-311135

HPS (2017) National Point Prevalence Survey of Healthcare Associated Infection and Antimicrobial Prescribing 2016, HPS. http://www.hps.scot.nhs.uk/resourcedocument.aspx?id=5964 (accessed $2^{\text {nd }}$ June 2017)

Hughes F (2016) Antimicrobial Resistance Journal of Psychosocial Nursing 54(7):13-14 doi: 10.3928/02793695-20160616-01

Mendelson M, Balasegaram M, Jinks T, Pulcini C, Sharland M (2017) Antibiotic resistance has a language problem. Nature 546: 23-25 doi: 10.1038/545023a

Michael CA, Dominey-Howes D, Labbate M (2014) The Antimicrobial Resistance Crisis: Causes, Consequences and Management. Front Public Health 2:145 doi: 10.3389/fpubh.2014.00145

Mustafa M, Wood F, Butler CC, Elwyn G (2014) Managing Expectations of Antibiotics for Upper Respiratory Tract Infections: A Qualitative Study. Ann Fam Med 12(1): 29-36 doi: 10.1370/afm.1583.

NHS, NSS (2012) National Infection Prevention and Control Manual. http://www.nipcm.hps.scot.nhs.uk/chapter-1-standard-infection-control-precautions-sicps/ (accessed $2^{\text {nd }}$ June 2017)

Ness V, Malcolm W, Reilly J (2015) Growth in nurse prescribing of antibiotics: the Scottish experience 2007-13. J Antimicrob Chemother 70(12): 3384-3389 doi: 10.1093/jac/dkv255

NICE (2017) Antimicrobial stewardship: changing risk-related behaviours in the general population. NICE guideline 63 https://www.nice.org.uk/guidance/ng63 (accessed $2^{\text {nd }}$ June 2017)

O’Neill (2016) Tackling drug-resistant infections globally: final report and recommendations the review on antimicrobial resistance https://amrreview.org/sites/default/files/160525 Final\%20paper with\%20cover.pdf (accessed $2^{\text {nd }}$ June 2017)

PHE (2016) A Framework for Personalised Care and Population Health for Nurses, Midwives, Health Visitors and Allied Health Professionals Caring for populations across the lifecourse https://www.qni.org.uk/wp-

content/uploads/2016/09/personalised care population health.pdf (accessed 2nd June 2017) 
PHE (2017) Antibiotic Guardian. http://antibioticguardian.com/ (accessed $2^{\text {nd }}$ June 2017)

Reilly J, Price L, Lang S, et al (2016) A pragmatic RCT of 6 step versus 3 step hand hygiene technique in acute hospital care Infect Control Hosp Epidemiol 37(6): 661-666 doi: 10.1017/ice.2016.51

RCN (2012) Nurse Prescribing in the UK. RCN Fact Sheet. http://www.rcn.org.uk/_data/assets/pdf_file/0008/443627/Nurse_Prescribing_in_the_UK -_RCN_Factsheet.pdf (accessed $2^{\text {nd }}$ June 2017)

RCN (2014) Antimicrobial resistance. RCN position on the nursing contribution. file://C:/Users/vne/Downloads/PUB-004681.pdf (accessed 2nd June 2017)

World Economic Forum (2017) Antibiotic resistance is the next great global challenge -we must act now https://www.weforum.org/agenda/2016/09/antimicrobial-resistance-is-thenext-global-commons-issue/ (accessed $2^{\text {nd }}$ June 2017)

WHO (2016a) Antimicrobial Resistance Factsheet. WHO. http://www.who.int/mediacentre/factsheets/fs194/en/ (accessed $2^{\text {nd }}$ June 2017)

WHO (2017a) Global priority list of antibiotic-resistant bacteria to guide research, discovery, and development of new antibiotics http://www.who.int/medicines/publications/WHO-PPLShort Summary 25Feb-ET NM WHO.pdf (accessed $2^{\text {nd }}$ June 2017)

WHO (2017b) SAVE LIVES: Clean Your Hands. WHO's global annual call to action for health workers http://who.int/infection-prevention/campaigns/clean-hands/en/ (accessed $2^{\text {nd }}$ June 2017)

WHO (2017c) Questions and answers on immunization and vaccine safety http://www.who.int/features/qa/84/en/ (accessed $2^{\text {nd }}$ June 2017)

WHO (2017d) Immunization factsheet http://www.who.int/mediacentre/factsheets/fs378/en/ (accessed $2^{\text {nd }}$ June 2017)

WHO (2015a) Antibiotic Resistance: Multi-country public awareness survey http://apps.who.int/medicinedocs/documents/s22245en/s22245en.pdf (accessed $2^{\text {nd }}$ June 2017)

WHO (2015b) Worldwide country situation analysis: response to antimicrobial resistance http://apps.who.int/iris/bitstream/10665/163468/1/9789241564946 eng.pdf?ua=1\&ua=1 (accessed $2^{\text {nd }}$ June 2017) 
Table 1: WHO priority pathogens list for R\&D of new antibiotics

\begin{tabular}{|c|c|}
\hline Priority 1: Critical & $\begin{array}{l}\text { - Acinetobacter baumannii, carbapenem-resistant } \\
\text { - Pseudomonas aeruginosa, carbapenem-resistant } \\
\text { - Enterobacteriaceae, carbapenem-resistant, ESBL-producing }\end{array}$ \\
\hline Priority 2: High & $\begin{array}{l}\text { - Enterococcus faecium, vancomycin-resistant } \\
\text { - Staphylococcus aureus, methicillin-resistant, vancomycin- } \\
\text { intermediate and resistant } \\
\text { - Helicobacter pylori, clarithromycin-resistant } \\
\text { - Campylobacter spp., fluoroquinolone-resistant } \\
\text { - Salmonellae, fluoroquinolone-resistant } \\
\text { - Neisseria gonorrhoeae, cephalosporin-resistant, } \\
\text { fluoroquinolone-resistant }\end{array}$ \\
\hline Priority 3: Medium & $\begin{array}{l}\text { - Streptococcus pneumoniae, penicillin-non-susceptible } \\
\text { - Haemophilus influenzae, ampicillin-resistant } \\
\text { - Shigella spp., fluoroquinolone-resistant }\end{array}$ \\
\hline
\end{tabular}

Table 2: The 7 key areas for future action from the UK AMR Strategy

\begin{tabular}{|l|l|}
\hline 1 & Improving infection prevention and control practices in human and animal health \\
\hline 2 & Optimising prescribing practice \\
\hline 3 & Improving professional education, training and public engagement \\
\hline 4 & Developing new drugs, treatments and diagnostics \\
\hline 5 & Better access to, and use of, surveillance data in human and animal sectors \\
\hline 6 & Better identification and prioritisation of AMR research needs \\
\hline 7 & Strengthened international collaboration \\
\hline
\end{tabular}

